\title{
Patient self care in acute asthma
}

\author{
BONNIE SIBBALD \\ From the Department of Clinical Epidemiology and Social Medicine, St George's Hospital Medical School, \\ London
}

ABSTRACT Psychosocial and other factors that may affect patient self care in acute asthma were investigated in 210 asthmatic adults recruited from general practice and hospital clinics. Interviews and self complete questionnaires were used to assess patients' management of a hypothetical slow onset and rapid onset attack of asthma, attitudes to asthma, family support, psychiatric morbidity, recent asthma morbidity, and knowledge of drug treatment. The patients with the highest morbidity from asthma delayed longest before taking appropriate action in the hypothetical acute attack. One in four patients expressed strong feelings of stigma and pessimism about being asthmatic, but attitudes were only weakly associated with behaviour. Other factors showed no significant relation to self care. The results suggest that there is no single important factor or group of factors governing patients' management of acute asthma. Health education might therefore prove more effective if it paid less attention to the possible cause or causes of poor self care and instead offered pragmatic advice on changing behaviour.

\section{Introduction}

Asthma continues to be an important cause of respiratory morbidity and mortality despite the availability of effective drug treatments. The reasons for this are not fully understood but poor self care appears to play an important part. Confidential inquiries into deaths from asthma in Britain and elsewhere have shown that patients' non-compliance with medical management, inappropriate actions during acute attacks, and failure to recognise the severity of acute asthma were factors that contributed to death. ${ }^{12}$ Other studies show these problems to be prevalent in patients who do not die..$^{3-6}$

Education of patients designed to reduce asthma morbidity by improving self care has so far achieved only limited success. Two large controlled trials have shown that such education may significantly improve knowledge but with no alteration in self management or morbidity. ${ }^{78}$ Other programmes, aimed at improving attitudes and motivation in addition to knowledge, have produced only a short term reduction in morbidity. ${ }^{9}$ One reason for this may be a lack of understan-

Address for reprint requests: Bonnie Sibbald, Department of General Practice and Primary Care, St George's Hospital Medical School, London SW17 ORE.

Accepted 14 November 1988 ding of the factors affecting self care, in particular the part played by patients' psychosocial characteristics.

Prospective hospital inpatient studies in the United States and The Netherlands have shown that feelings of stigma and pessimism about asthma, and a panicky or fearful response to attacks, are related to length of stay in hospital, intensity of prescribed medication, and frequencies of hospital admission. ${ }^{10-11}$ Other research suggests that there may be an association between a low level of social support for a patient, recent life change, and a higher dose of oral corticosteroids required to control the asthma. ${ }^{12}$ Psychosocial factors might therefore play an important part in the maintenance of asthma morbidity.

The aim of the present study was to further the development of effective health education for asthma by investigating psychosocial and other factors that might influence self care in acute asthma. We hoped to identify the factors that health education would be most likely to prove effective in influencing to reduce asthma morbidity.

\section{Methods}

\section{PATIENTS}

The study consisted of adults, aged 16 years or over, who had been diagnosed by their physician as having asthma and who had received anti-asthma medication 
within the previous six months. The age limit was set to ensure that patients were old enough to take responsibility for their own health. Eligible patients were recruited from a district general hospital in Surrey and four group general practices in the surrounding suburban area. In the hospital names and addresses of consecutive patients fulfilling the entry criteria were provided by the consultant in chest medicine. In the general practices eligible patients were identified by scrutiny of the medical records of patients listed in asthma disease registers.

\section{INTER VIEW AND QUESTIONNAIRES}

Patients were sent letters explaining the purpose of the study and inviting their participation. I interviewed those who agreed in their homes. The information recorded at interview included patients' age, sex, social class, age at onset of asthma and its duration, asthma morbidity in the past six months, current anti-asthma treatment, and other medical problems.

The 30 question General Health Questionnaire (GHQ30) was used to identify probable psychiatric illness. ${ }^{13}$ The questionnaire consisted of 30 items relating to psychiatric distress, for which the patient was asked to compare his present state with his usual state using a four point scale $(1=$ not at all, $4=$ much more than usual). A total score was calculated by summing the number of items said to occur more often than usual (that is, scores 3 and 4).

Family support was assessed by methods of the family APGAR questionnaire. ${ }^{14}$ The questionnaire consisted of five items describing family functioningnamely, succour, partnership, adaptation to change, affection, and time sharing. Patients indicated their experience of each item on a five point scale with end points "always" and "never." Responses were coded on a scale from 1 (least support) to 5 (most support) for each item and the values were then summed to give an overall measure of the patients' level of family support.

Patients' attitudes and beliefs about asthma were assessed by means of a self complete questionnaire developed by us for this purpose..$^{15}$ The questionnaire consisted of 31 statements regarding attitudes and beliefs thought to be important in determining illness behaviour in asthma. Patients indicated their view of each item on a four point scale with end points "strongly agree" and "strongly disagree." Responses were coded on a scale from 1 (least positive attitude) to 4 (most positive attitude) for each item. Factor analysis was used to place items in subgroups representing different aspects of patients' attitudes. Principal component analysis was then used to devise a factor score, equal to the best linear combination of items within each factor.

Management of acute attacks was assessed by asking patients to describe the actions they would take in response to each of two hypothetical attacks, one increasing gradually in severity over the course of a week and the other developing rapidly over the course of an hour (appendix). Each scenario was presented in three parts, the patient indicating the action he or she would take at the end of each part. Both scenarios ended with the patient feeling so wheezy and breathless that it was difficult to speak or rise from a chair. Responses were coded as the point during an attack when patients would initiate each of the following six activities: perform a non-drug manoeuvre, inhale a bronchodilator, take an oral bronchodilator, inhale a corticosteroid or cromoglycate, take an oral steroid, and seek medical assistance. This method of assessment was adapted from that used by Avery $e t a{ }^{\beta}$ to assess self care in acute asthma.

\section{STATISTICAL ANALYSES}

The significance of differences between variables was assessed by the $\chi^{2}$ test. The Kendall coefficient of correlation ( $r$ ) was used to measure the degree of association between variables.

Factor analysis and principal component analysis were carried out as described by $\mathrm{Kim} .{ }^{16}$ Factor analytic techniques reduce a large number of variables to a smaller set of "factors," each representing some underlying pattern of relationship in the data. This is accomplished by grouping together variables that are highly correlated with each other but not correlated with the variables composing other factors. Principal component analysis was used to compute a "factor score," which represents the best linear combination of variables (within a factor), determined by maximising the amount of variance explained by the factor.

\section{Results}

\section{PATIENTS}

Three hundred and forty patients were identified as eligible for the study: 281 in the general practices and 59 attending hospital. Of these, $211(62 \%)$ agreed to participate, $169(60 \%)$ from general practice and 42 (71\%) from hospital. One patient who agreed to take part was too agitated at interview to be included, leaving 210 patients available for study.

Patients ranged in age from 16 to 85 (mean 45) years and their ages at onset of asthma ranged from 1 to 79 (median 18) years. The duration of asthma ranged from 1 to 70 (median 19) years. Morbidity reported by patients due to asthma in the previous six months was high - as was expected, because patients were selected through recent contact with medical services (table 1). Seventy nine patients $(38 \%)$ scored 5 or above on the General Health Questionnaire, indicating probable psychiatric illness. ${ }^{12}$ One hundred and forty nine patients $(71 \%)$ scored at least 20 out of a possible 25 
Table 1 Morbidity due to asthma reported by 210 patients in the previous six months

\begin{tabular}{llc}
\hline Index of morbidity & & No (\%) \\
\hline $\begin{array}{l}\text { Symptoms } \\
\text { Wheezy attacks }\end{array}$ & More than 2 weekly & $43(20)$ \\
Nocturnal attacks & More than 2 weekly & $70(33)$ \\
Overall trouble & Moderate/severe & $99(47)$ \\
Disability & Walking on level & $59(28)$ \\
Exercise dyspnoea & Walking uphill & $131(62)$ \\
& Climbing stairs & $112(53)$ \\
Absent from work/school & At least once & $35(27)$ \\
Overall interference & Moderate/severe & $60(29)$ \\
Use of medical service & At least once & $26(12)$ \\
GP home visit & At least once & $12(6)$ \\
Casualty & At least once & $15(7)$ \\
Hospital admission & &
\end{tabular}

points on the family APGAR questionnaire, indicating good family support.

\section{ATTITUDES TO ASTHMA}

Factor analysis of the "attitudes" questionnaire identified three aspects or components of patients' attitudes towards asthma that together accounted for $65 \%$ of the overall variance in responses (table 2 ). Factor 1 dealt with feelings of stigma and pessimism, factor 2 with confidence in the doctor, and factor 3 with self confidence in managing attacks. Negative attitudes to three or more of the five items composing a factor were expressed by $52(25 \%)$ patients in relation to factor $1,34(16 \%)$ in relation to factor 2 , and 21 $(10 \%)$ in relation to factor 3.

\section{KNOWLEDGE OF DRUG TREATMENTS}

Inhaled bronchodilators were the most commonly

Table 2 Attitudes to asthma among the 210 patients

\begin{tabular}{|c|c|c|}
\hline \multirow{2}{*}{$\cdots$} & Agree & Disagree \\
\hline & \multicolumn{2}{|c|}{ (Number (\%)) } \\
\hline $\begin{array}{l}\text { Factor 1: Stigma } \\
\text { Feels different from others } \\
\text { Feels angry } \\
\text { Feels depressed } \\
\text { Feels somehow to blame } \\
\text { Can't enjoy a full life }\end{array}$ & $\begin{array}{l}55(26) \\
80(38) \\
67(32) \\
27(13) \\
82(39)\end{array}$ & $\begin{array}{l}155(74) \\
130(62) \\
143(68) \\
183(87) \\
128(61)\end{array}$ \\
\hline $\begin{array}{l}\text { Factor 2: Confidence in doctor } \\
\text { Doctor has helped asthma } \\
\text { Confidence in doctor } \\
\text { Avoids doctor } \\
\text { Can talk to doctor } \\
\text { Doctor informative }\end{array}$ & $\begin{array}{l}178(85) \\
192(91) \\
130(62) \\
139(66) \\
156(74)\end{array}$ & $\begin{array}{l}32(15) \\
18(8) \\
80(38) \\
71(34) \\
54(26)\end{array}$ \\
\hline $\begin{array}{l}\text { Factor 3: Self confidence in self care } \\
\text { Confident can cope } \\
\text { Can recognise onset } \\
\text { Can prevent attacks } \\
\text { Doesn't fear attacks } \\
\text { No panic at onset }\end{array}$ & $\begin{array}{l}189(90) \\
190(90) \\
118(56) \\
174(83) \\
163(78)\end{array}$ & $\begin{array}{l}21(10) \\
20(9) \\
92(44) \\
36(17) \\
47(22)\end{array}$ \\
\hline
\end{tabular}

used medication $(195,93 \%)$, followed by inhaled corticosteroids $(114,54 \%)$, oral bronchodilators $(104$, $49 \%)$, oral corticosteroids $(50,24 \%)$. inhaled cromoglycates $(40,19 \%)$, and other drugs $(14,7 \%)$. Drugs were correctly identified as "relieving" or "preventing" symptoms or both in 403 of 517 (78\%) cases.

\section{PATIENTS' RESPONSE TO HYPOTHETICAL ASTHMA ATTACKS (table 3)}

In a slow onset attack as many as $40(19 \%)$ patients would have delayed seven days before seeking medical help, and a further $11(5 \%)$ would not have called a doctor even then. In a rapid onset attack $35(17 \%)$ would not have summoned help, despite finding it difficult to speak or rise from a chair.

Self care in the acute attacks showed few associations with patients' demographic characteristics. Delay in using an inhaled bronchodilator was significantly associated with older age $\left(\chi^{2}=26 \cdot 1\right.$, df $=8, \mathrm{p}<0.01)$, retirement $\left(\chi^{2}=7.3\right.$, df $=2$, $p<0.05)$, a late age at onset of asthma $\left(\chi^{2}=13.5\right.$, df $=4, p<0.01$, , and having other medical problems $\left(\chi^{2}=3.9, \mathrm{df}=2, \mathrm{p}<0.05\right)$. After age had been controlled for, however, the other associations were no longer significant.

Several associations were found between high levels of asthma morbidity and delay in taking remedial action in acute attacks. (1) Delay in using a bronchodilator inhaler during acute attacks was weakly correlated with increased dyspnoea while going up hills $(r=0.14, p<0.05)$ and stairs $(r=0.14$, $\mathrm{p}<0.05$ ). (2) Delay in taking oral bronchodilators was weakly correlated with increased dyspnoea while going up stairs $(r=0.19, p<0.05)$ and greater overall trouble with asthma in the past six months $(r=0.20, p<0.05)$. (3) Delay in summoning medical help was weakly correlated with increased

Table 3 Self care in acute asthma: response of the 210 patients to a hypothetical attack

\begin{tabular}{lcccc}
\hline \multicolumn{5}{c}{ Action initiated (number (\%)) } \\
\cline { 2 - 5 } Action taken & Immediately & Short delay & Long delay & Not at all \\
\hline Slow onset attack & & & \\
Inh B & $133(67)$ & $7(4)$ & $0(0)$ & $59(30)$ \\
Oral B & $22(22)$ & $7(3)$ & $0(0)$ & $72(71)$ \\
Inh St & $40(27)$ & $6(4)$ & $0(0)$ & $102(69)$ \\
Oral St & $11(22)$ & $13(26)$ & $3(6)$ & $23(46)$ \\
Call doctor & $52(25)$ & $107(51)$ & $40(19)$ & $11(5)$ \\
Rapid onset attack & & & \\
Inh B & $141(71)$ & $41(21)$ & $1(4)$ & $15(8)$ \\
Oral B & $6(6)$ & $20(20)$ & $6(6)$ & $69(68)$ \\
Inh St & $22(15)$ & $14(10)$ & $2(1)$ & $109(74)$ \\
Oral St & $1(2)$ & $5(10)$ & $6(12)$ & $39(76)$ \\
Call doctor & $2(1)$ & $65(31)$ & $107(51)$ & $35(17)$ \\
\hline
\end{tabular}

Inh B-inhaled bronchodilator; oral B-oral bronchodilator; inh St-inhaled steroid; oral St-oral steroid. 
frequency of attacks $(r=0.12, p<0.05)$ and nocturnal waking $(r=0.14, p<0.05)$, increased dyspnoea while walking $(\mathrm{r}=0.12, \mathrm{p}<0.05)$, and greater overall interference with everyday activities $(\mathrm{r}=0.13, \mathrm{p}<0.05)$.

Patients' attitudes to asthma were also associated with their management of attacks. In a rapidly developing acute attack immediate use of inhaled bronchodilators was associated with a strong sense of stigma $\left(\chi^{2}=8.4\right.$, df $\left.=4, p=0.08\right)$ and with low levels of self confidence in managing attacks $\left(\chi^{2}=10.4, \mathrm{df}=4, \mathrm{p}=0.03\right)$. In a slow onset attack delay in taking oral bronchodilators was associated with high levels of confidence in the doctor $\left(\chi^{2}=7 \cdot 1, \mathrm{df}=2, \mathrm{p}=0.03\right)$. No other significant associations were found.

No significant associations were found between the patients' response to a hypothetical attack and their knowledge of their own drug treatment, the presence or absence of psychiatric illness (as shown by the General Health Questionnaire), or degree of family support (as shown by the family APGAR questionnaire).

\section{Discussion}

Good self care is essential in a chronic intermittent condition such as asthma. Patients must be alert to changes in morbidity and take appropriate action to relieve acute attacks. Poor self care may result in increased morbidity and mortality.

This study supports others in showing that many patients may make serious errors in their management of attacks. Delay in seeking medical help and inappropriate use of drugs were the most important problems identified here. In a rapidly developing acute attack as many as $17 \%$ of patients would not summon medical help despite finding it difficult to speak or rise from a chair. The response to a slowly developing attack was little different-19\% would allow their asthma to deteriorate for seven days before seeking medical help and a further $5 \%$ would not call a doctor even then. Many patients would not increase their use of bronchodilator drugs in an acute attack, and others would raise the dose of both prophylactic and symptomatic medication.

Very few factors were found to influence self care in acute asthma. Older patients were less likely than younger ones to increase their use of bronchodilator inhalers-perhaps because the old were less flexible in their behaviour than the young. There were no other significant associations between self care (as judged by the response to a hypothetical attack of asthma) and patients' age, sex, social class, age at onset and duration of asthma, psychiatric morbidity (as shown by the General Health Questionnaire), or family support (as shown by the family APGAR question -: naire). Nor was there any significant association between self care and patients' knowledge of their drugo treatment.

Patients who felt stigmatised or lacked confidence in $\frac{\overline{\bar{s}}}{\overline{2}}$ their management tended to use bronchodilator ${ }^{\Phi}$ inhalers early in an acute attack. This finding complements that of Jones and colleagues, who showed ${ }^{\text {s }}$ that a panicky or fearful attitude to attacks was. associated with excessive use of inhalers among hos $-\overrightarrow{\vec{\omega}}$ pital inpatients. ${ }^{10}$ Reducing the sense of stigma might ${ }^{\circ}$ reduce inhaler use, but the likely benefit is questionable as the prompt use of bronchodilators in acute asthma is thought to be a desirable therapeutic ${ }_{i}^{+}$ intervention. The impact on behaviour is likely to beco small in any case as the association of attitudes with self care in this study was weak, suggesting that there are other, more important factors governing patients' behaviour.

Morbidity was the factor found to be most strongly을 associated with self care. Patients with the highest reported morbidity in the past six months were those who would delay longest before using bronchodilators $\odot$ or summoning medical help. This finding contradicts. ${ }^{\circ}$ models of patient behaviour, such as the Health Belief Model, ${ }^{17}$ in which perceived morbidity is viewed as an incentive to good self care. Instead, the data suggest that chronic severe asthma may foster indifference to acute asthma, leading patients to delay in taking $\stackrel{\mathbb{\perp}}{\circ}$ appropriate action.

Clearly more needs to be done to improve self care $\frac{3}{3}$ in acute asthma. But how is this to be achieved? The present study suggests that there is no single importanto factor or group of factors governing self care. In particular, patients' knowledge of their drug treatment 으 and attitudes towards their condition appeared to $\underset{\times}{\sim}$ have little affect on their management of acute asthma. Health education aimed at improving these factors is $\underline{3}$. therefore unlikely to have any appreciable benefits. A $ᄋ$ better approach might be to focus on changing undesirable behaviour without regard to its origin. 을 Certainly teaching patients how to cope with chronic $\square$ disease has proved more successful in reducing mor-은 bidity than have programnmes designed principally to improve patients' knowledge. ${ }^{18}$ In this context, the ? hypothetical attack scenarios described here proved a $\cong$ simple and effective method of identifying self care $\mathcal{W}^{N}$ problems, and might additionally be helpful in teaching patients more appropriate strategies.

I am grateful to the Department of Health and Social $\stackrel{\oplus}{\oplus}$ Security for financial support of this work. I would 0 also like to thank Drs Ralph Burton, Clifford Floyd, o Sean Hilton, Geoffrey Knowles, and Lydia Smythe for $\stackrel{\mathbb{\Omega}}{\Omega}$ their assistance in recruiting patients, and Professors $\stackrel{\mathbb{\Phi}}{\mathbb{Q}}$ H R Anderson and P Freeling for their helpful $\frac{\varrho}{O}$ comments and criticisms throughout. 


\section{Appendix: Hypothetical asthma attacks}

SLOW ONSET ATTACK

Days 1-3 For the last two days you have been feeling a little more wheezy and breathless than usual, but not enough to interfere with your everyday activities. Last night you woke up once because of asthma, but were able to get to sleep again easily. This morning you again wake up feeling more wheezy and breathless than usual.

ACTION?

Days 4-5 Your breathing got slightly worse over the next two days and you found it increasingly difficult to get on with your everyday activities. Last night you were wakened twice because of asthma and found it difficult to get back to sleep. Today you wake earlier than usual and are feeling very wheezy and breathless.

ACTION?

Days 6-7 Your wheezing and breathlessness got worse over the next day. Last night you wakened three times because of asthma and the last time you couldn't get back to sleep. It's now morning and you're so wheezy and breathless that you find it difficult to speak or walk across the room.

ACTION?

\section{RAPID ONSET ATTACK}

Start You woke this morning feeling perfectly well and spent the day doing your usual activities. At 7 o'clock in the evening you sit down to relax and notice you're feeling a little wheezy and breathless.

ACTION?

$30 \mathrm{~min}$ The wheezing and breathlessness get worse over the next half hour and you find it a little difficult to walk to the kitchen for a drink.

ACTION?

One hour Your breathing continues to get worse and by 8 o'clock you're so wheezy and breathless that you find it difficult to speak or get up from your chair.

ACTION?

\section{References}

1 British Thoracic Association. Death from asthma in two regions of England. Br Med J 1982;285:1251-5.

2 Rea H, Scragg R, Jackson R, Beaglehole R, Fenwick J, Sutherland D. A case-control study of deaths from asthma. Thorax 1986;41:833-9.

3 Avery C, March J, Brook R. An assessment of the adequacy of self-care by adult asthmatics. $J$ Commun Health 1980;5:167-80.

4 Harding J, Modell M. How patients manage asthma. $J \boldsymbol{R}$ Coll Gen Pract 1985;35:226-8.

5 Partridge $M$. Asthma education: more reading or more viewing? J R Soc Med 1986;79:326-8.

6 Ellis M, Friend J. How well do asthma clinic patients understand their asthma? Br J Dis Chest 1985;79:43-8.

7 Hilton S. Patient education in asthma. Family Practice 1986;3:44-8.

8 Jenkinson D, Davison J, Jones S, Hawtin P. Comparison of effects of a self-management booklet and audiocassette for patients with asthma. Br Med J 1988; 297:267-70.

9 Hilton S, Sibbald B, Anderson HR, Freeling P. Controlled evaluation of the effects of patient education on asthma morbidity in general practice. Lancet 1986; i:26-9.

10 Jones N, Kinsman R, Dirks J, Dahlem N. Psychological contributions to chronicity in asthma: patient response styles influencing medical treatment and its outcome. Med Care 1979;17:1103-18.

11 Kaptein A. Psychological correlates of length of hospitalization and rehospitalization in patients with acute, severe asthma. Soc Sci Med 1982;16:725-9.

12 Araujo G, Arsdel P, Holmes T, Dudley D. Life change, coping ability and chronic intrinsic asthma. J Psychosom Res 1973;17:359-63.

13 Goldberg D, Rickels K, Dowing R, Hesbacher P. A comparison of two psychiatric screening tests. $\mathrm{Br} \mathrm{J}$ Psychiatry 1976;129:61-7.

14 Smilkstein G, Ashworth C, Montano D. Validity and reliability of the family APGAR as a test of family function. Journal of Family Practice 1982;15:303-11.

15 Sibbald B, Collier J, D'Souza M. Questionnaire assessment of patients' attitudes and beliefs about asthma. Family Practice 1986;3:37-41.

16 Kim J. Factor analysis. In: Nie N, Hull C, Jenkins J, Steinbrenner K, Bent D, eds. SPSS: statistical package for the social sciences. New York: McGraw-Hill, 1975:468-514.

17 Becker M, Haefner D, Kasl S, Kirscht J, Maiman L, Rosenstock I. Selected psychological models and correlates of individual health-related behaviours. Med Care 1977;15(suppl):27-46.

18 Mazzuca S. Does patient education in chronic disease have therapeutic value? J Chron Dis 1982;35:521-9. 